
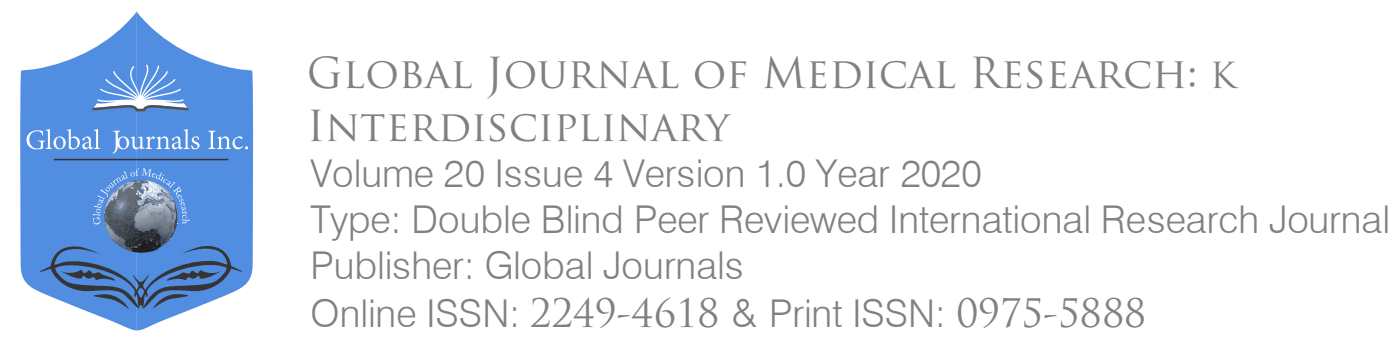

\title{
Comparison between Threshold of Sourness Perception and Blood Pressure for Resident Health Examination in Yakumo Town
}

By Naomi Katayama, Mayumi Hirabayashi, Akemi Ito, Shoko Kondo, Yui Nakayama, Takafumi Nakada, Seiya Goto, Satofumi Sugimoto, Tadao Yoshida, Masaaki Teranisi, Michihiko Sone, Yasushi Fujimoto, Hironao Otake, Hirokazu Suzuki, Naoki, Saji, Seiichi Nakata, Tsutomu Nakashima, Kenji Kondo \& Takaki Miwa

Nagoya Women's University

Abstract- Since Japan is a super-aged society, various problems are occurring for the elderly. The nutritional problems of the elderly are complex, and measures currently took to solve the one by focusing on malnutrition-related items. Therefore, in this study, we focused on the sourness, which can identify the spoilage of food and could be expected to reduce salt. For 16 years, we have conducted research on taste and olfaction in Yakumo town in Hokkaido, Japan, Where the population does not move much. In this report, we report on the results of the taste test using TASTDISC (Sourness) in 2019 at Yakumo Town Resident Examination, which has been ongoing since 2007. From the database, 298 participants (169 females and 129 males) were selected form data in August 2019.

Keywords: sourness; gender; healthy elderly people; taste function; yakumo study.

GJMR-K Classification: NLMC Code: WB 280

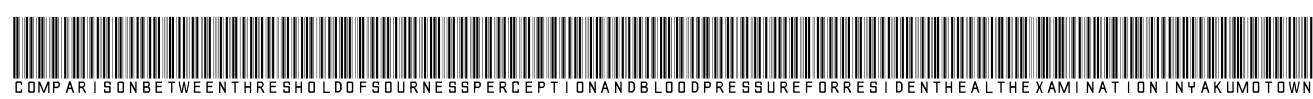

Strictly as per the compliance and regulations of:

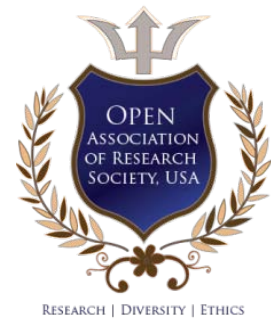

(c) 2020. Naomi Katayama, Mayumi Hirabayashi, Akemi Ito, Shoko Kondo, Yui Nakayama, Takafumi Nakada, Seiya Goto, Satofumi Sugimoto, Tadao Yoshida, Masaaki Teranisi, Michihiko Sone, Yasushi Fujimoto, Hironao Otake, Hirokazu Suzuki' Naoki, Saji, Seiichi Nakata, Tsutomu Nakashima, Kenji Kondo \& Takaki Miwa. This is a research/review paper, distributed under the terms of the Creative Commons Attribution-Noncommercial 3.0 Unported License http://creativecommons.org/licenses/by$\mathrm{nc} / 3.0 /$ ), permitting all non-commercial use, distribution, and reproduction in any medium, provided the original work is properly cited. 


\title{
Comparison between Threshold of Sourness Perception and Blood Pressure for Resident Health Examination in Yakumo Town
}

\author{
Naomi Katayama ${ }^{\alpha}$, Mayumi Hirabayashi ${ }^{\circ}$, Akemi Ito ${ }^{\circ}$, Shoko Kondo ${ }^{\omega}$, Yui Nakayama ${ }^{*}$, \\ Takafumi Nakada ${ }^{\S}$, Seiya Goto ${ }^{x}$, Satofumi Sugimoto ${ }^{\vee}$, Tadao Yoshida ${ }^{\ominus}$, Masaaki Teranisi ${ }^{`}$, \\ Michihiko Sone ${ }^{\ddagger}$, Yasushi Fujimoto ${ }^{\ddagger}$, Hironao Otake ${ }^{\ddagger}$, Hirokazu Suzuki ${ }^{z}$ Naoki, Saji ${ }^{\ddagger}$, Seiichi Nakata ${ }^{\circledR}$, \\ Tsutomu Nakashima ${ }^{₫}$, Kenji Kondo ${ }^{m}$ \& Takaki Miwa ${ }^{\complement}$
}

Abstract- Since Japan is a super-aged society, various problems are occurring for the elderly. The nutritional problems of the elderly are complex, and measures currently took to solve the one by focusing on malnutrition-related items. Therefore, in this study, we focused on the sourness, which can identify the spoilage of food and could be expected to reduce salt. For 16 years, we have conducted research on taste and olfaction in Yakumo town in Hokkaido, Japan, Where the population does not move much. In this report, we report on the results of the taste test using TASTDISC (Sourness) in 2019 at Yakumo Town Resident Examination, which has been ongoing since 2007. From the database, 298 participants (169 females and 129 males) were selected form data in August2019. The sourness test performed using the sourness test paper with liquid TASTEDISC (Sanwa Chemical Laboratory Co., Ltd) which include five different densities of Tartaric acid on a liquid with test paper namely:, $1(0.02 \%), 2(0.2 \%), 3(2.0 \%)$, $4(4.0 \%), 5(8.0 \%)$. As a result, 17 males out of 129 male participants (13.2\%) and tenfemales of 169 female participants (5.9\%) had abnormal values in sour taste test (Tastedisc) results. The tolerance range (in this study, it called the normal range) of sourness, blood pressure (systole, diastole), and body composition (BMl, body fat percentage, abdominal circumference) compared with other values. As a result, there was no statistically significant difference in the sourness threshold between the normal range of blood pressure, BMI, and others. However, there was a statistically significant difference in the result of sourness between the normal range of body fat percentage and the other one. And also, in female

Corresponding Author a: Nagoya Women's University, Nagoya City, Japan.e-mail:naomik@nagoya-wu.ac.jp

Author $\alpha \sigma \rho$ : Graduate School of Nagoya Women's University, Nagoya City, Japan.

Author $\alpha \rho \chi v \theta \zeta £ €$ : Department of Otorhinolaryngology, Nagoya University Graduate School of Medicine, Nagoya, Japan

Author w: Watanabe Hospital, Mihama town, Noma, Aichi, Japan

Author $¥$ : Nagoya cooking School, Nagoya, Aichi, Japan

Author $\S$ z \%: National Center for Geriatrics and Gerontology, Obu, Japan.

Author F: Otake Otolaryngology Hospital, Kariya City, Aichi, Japan.

Author A: Department of Otolaryngology, Second Hospital Fujita Health University School of Medicine, Nagoya, Japan.

Author d: Ichinomiya Medical Treatment \& Habitaiton Center, Ichinomiya, Japan.

Author m: Kanazawa Medical University, Japan.

Author \&: Graduate School of Medical Sciences, The University of Tokyo, Japan. cases, participants with a long waist circumference had a statistically significant lower sourness threshold than those with short waist circumference. Feeling sourness can also protect us from ingesting dangerous foods (corruption and poison). We would like to increase the number of participants and clarify the relationship between sourness, eating habits, and other factors.

Keywords: sourness; gender; healthy elderly people; taste function; yakumo study.

\section{INTRODUCTION}

$\circlearrowleft$ ince Japan is a super-aged society, various problems are occurring for the elderly. There are many older asults on the waiting list to get into the welfare facilities, and many households forced to provide home care. The nutritional problems of the elderly are complex, and measures currently took to solve it by focusing on malnutrition-related items such as flail, sarcopenia, and locomotive syndrome. One of the causes of under nutrition is the phenomenon of nutrient intake due to the difficulty of understanding the taste, loss of appetite, and reduction of the total diet. Flavors, that is, matching both taste and smell, are need in a diet, and low thresholds for typical five tastes (sweetness, saltiness, sourness, bitterness, and umami) affect health. Therefore, in this study, we focused on the sourness, which can identify the spoilage of food and can expect to reduce salt.

\section{il. Materials and Methods}

\section{a) Participants}

The participants were community dwellers who voluntarily participated in the Yakumo Study and had managed their everyday life themselves. The Yakumo Study conducted since 1981 as a joint project between the town of Yakumo in Hokkaido and the Nagoya University Graduate School of Medicine. Professionals in the fields of epidemiology, internal medicine, orthopedics, neuropsychology, ophthalmology, otolaryngology, and urology joined the Yakumo Study. The analyzed data were based on the database to2019 from the neuropsychology and otolaryngology teams. 
The participants had been engaged in a variety of jobs, not only white-collar but also in agriculture, fishery, and forestry. Therefore, this town can regard as representative of today's Japanese society. From the database, 297participants (168 females and 129 males) were selected form data in August 2019 (Table 1).

Table 1: Age composition of participants in Yakumo inhabitants examination $(n=297)$.

\begin{tabular}{lccccc}
\hline Participants & 40's & 50's & 60's & 70's & 80's \\
\hline Male (129) & 10 & 24 & 49 & 39 & 6 \\
Female (168) & 23 & 40 & 65 & 38 & 3 \\
Total (297) & 33 & 64 & 114 & 77 & 9 \\
\hline
\end{tabular}

\section{b) Assessment of sweetness taste identification}

The sourness test performed using test paper with liquid TASTEDISC (Sanwa Chemical Laboratory Co., Ltd) which include five different densities of Tartaric acid on a liquid with test paper namely:, 1(0.02\%), $2(0.2 \%), 3(2.0 \%), 4(4.0 \%), 5(8.0 \%)$. The inspection method is as follows. 1) Show participants the taste choice paper: Sweet, Salty, Sour, Bitter. Taste something, but I don't know, No taste. 2) Hold the filter paper with tweezers. The sweetening solution is dropped on the disc and moistened. 3) The moistened disc gently placed on the canaliculus chordae tympani innervation area of the participant's tongue. The canaliculus chordae tympani innervation area is located $2 \mathrm{~cm}$ left and right from the tip of it. 4) Instruct the user to answer one of the taste choice paper in $2 \sim 3$ seconds with the mouth open. 5) The examiner then removes the disc from the participant's tongue with tweezers. 6) If a correct answer is not obtained, the test is continued using a solution having a higher concentration in order. 7) After garglling with water to prevent residual teste, perform the next taste test at intervals of 1 minute or more. This method was in accordance with the test method of the teste test kit (TASTEDISC: Sanwa Chemical Laboratory Co., Ltd ).

c) Ethical review board

This study conducted with the approval of the Ethical Review Board (Nagoya women's university

Table 2: Souriness test (Tastedisc) results and blood pressure and body composition results (Average for Males in their 40's to 80's)

\begin{tabular}{|c|c|c|c|c|c|c|c|c|c|}
\hline & Number & Age & $\begin{array}{l}\text { Height } \\
\text { cm }\end{array}$ & $\begin{array}{c}\text { Weight } \\
\text { g }\end{array}$ & $\begin{array}{l}\text { Waist } \\
\text { cm }\end{array}$ & $\begin{array}{c}\text { BMI } \\
\mathrm{kg} / \mathrm{m} / \mathrm{m}\end{array}$ & $\begin{array}{l}\text { Body fat } \\
\text { rate } \\
\%\end{array}$ & $\begin{array}{l}\text { Systolic blood } \\
\text { pressure } \\
\text { mmHg }\end{array}$ & $\begin{array}{c}\text { Dyastolic blood } \\
\text { pressure } \\
\text { mmHg }\end{array}$ \\
\hline Average of 40's Male & 10 & 45.5 & 170.1 & 74.2 & 84.8 & 25.7 & 23.7 & 136.8 & 80.9 \\
\hline Average of 50's Male & 24 & 54.8 & 168.0 & 71.3 & 86.7 & 25.4 & 24.4 & 131.0 & 81.3 \\
\hline Average of 60's Male & 49 & 64.8 & 167.3 & 68.9 & 86.5 & 24.6 & 24.7 & 138.3 & 83.1 \\
\hline Average of 70's Male & 40 & 73.0 & 164.7 & 66.2 & 84.6 & 24.4 & 23.7 & 145.5 & 79.7 \\
\hline Average of 80's Male & 6 & 84.8 & 159.1 & 63.5 & 87.4 & 25.1 & 24.3 & 134.7 & 66.2 \\
\hline Total average of Male & 129 & 64.9 & 166.4 & 68.7 & 85.8 & 24.8 & 24.2 & 138.9 & 80.8 \\
\hline
\end{tabular}

Ethics Committee: 'hitowo mochiita kennkyuuni kansuru iinnkai'). The approval number is 30-14.

\section{d) Statistical processing}

The test results were confirmed to be normal distribution by F-test. Data that were the tolerance range (in this study, it called the normal range) distributed were compared with Student-t without correlation of parametric test. The data that is not normally distributed was compared without correlated Mann-Whitney one of the non-parametric test.

\section{Results}

\section{a) Participant's body composition and}

Data on body composition and blood pressure of participants showed by age. The males showed in Table 2. And the females are shown in Table 3. All data showed as averages by age. For both males and females, the mean values of blood pressure for each one were in the normal range. Body fat percentage was higher in females than in males, and BMI and body fat were almost tolerance range (in this study, it called the normal range) for both males and females. 
Table 3: Sourness test (Tastedisc) results and blood pressure and body composition results (Average for Females in their 40's to 80 's)

\begin{tabular}{|c|c|c|c|c|c|c|c|c|c|}
\hline & Number & Age & $\begin{array}{c}\text { Height } \\
\text { cm }\end{array}$ & g & $\begin{array}{c}\text { Waist } \\
\text { cm }\end{array}$ & $\begin{array}{c}\text { BMI } \\
\text { kg/m/m }\end{array}$ & $\begin{array}{c}\text { Body fat } \\
\text { rate } \\
\%\end{array}$ & $\begin{array}{c}\text { Systolic blood } \\
\text { pressure } \\
\text { mmHg }\end{array}$ & $\begin{array}{c}\text { Dyastolic blood } \\
\text { pressure } \\
\text { mmHg }\end{array}$ \\
\hline Average of 40's Female & 23 & 45.2 & 158.0 & 57.2 & 76.7 & 22.8 & 33.2 & 122.3 & 70.1 \\
\hline Average of 50's Female & 40 & 54.3 & 155.5 & 56.4 & 76.8 & 23.3 & 33.4 & 131.6 & 77.4 \\
\hline Average of 60's Female & 66 & 64.5 & 153.8 & 55.7 & 77.7 & 23.5 & 33.9 & 137.1 & 77.0 \\
\hline Average of 70's Female & 37 & 72.8 & 150.6 & 52.8 & 76.2 & 23.3 & 33.1 & 140.1 & 74.7 \\
\hline Average of 80's Female & 3 & 82.0 & 147.4 & 49.6 & 78.1 & 22.9 & 31.1 & 149.0 & 77.0 \\
\hline Total average of Female & 169 & 61.6 & 154.0 & 55.3 & 77.0 & 23.3 & 33.4 & 134.7 & 75.7 \\
\hline
\end{tabular}

b) Simple sourness threshold test result

Sour taste identification performed by using test

paper TASTDESC (Sanwa Chemical Laboratory Co.,

Ltd). Table 4 shows the Sourness measurement results

for male and female by age. The sourness test

performed using the sourness test paper with liquid

TASTEDISC (Sanwa Chemical Laboratory Co., Ltd)

which include five different densities of Tartaric acid on a liquid with test paper namely:, 1(0.02\%), 2(0.2\%),3(2.0\%), 4(4.0\%), 5(8.0\%). As a result, 17 males out of 129 male participants (13.2\%) and ten females of 169 female participants (5.9\%) had abnormal values in sour taste test (TASTEDISC) results. The normal range for males was $44.2 \%$, and the normal range for females was $46.2 \%$.

Table 4: Sourness test (Tastedisc) results (Number of Males in their 40's to 80's)

\begin{tabular}{|c|c|c|c|}
\hline & & Tastedisc & \\
\hline$(\mathrm{n}=298)$ & $\begin{array}{c}\text { Normal } \\
0.02 \%, 0.20 \% \\
\end{array}$ & $\begin{array}{l}\text { Observation } \\
2.0 \%, 4.0 \%\end{array}$ & $\begin{array}{l}\text { Consultation } \\
8.0 \% \text { ormore }\end{array}$ \\
\hline Male 40's $(n=10)$ & 6 & 4 & o \\
\hline Male 50's $(n=24)$ & 10 & 10 & 4 \\
\hline Male 60's (n=49) & 24 & 17 & 8 \\
\hline Male 70's $(n=40)$ & 16 & 21 & 3 \\
\hline Male 80's $(n=6)$ & 1 & 3 & 2 \\
\hline Male total $(n=129)$ & 57 & 55 & 17 \\
\hline Female 40's (n=23) & 16 & 6 & 1 \\
\hline Female 50's (n=40) & 20 & 19 & 1 \\
\hline Female 60's (n=66) & 26 & 34 & 6 \\
\hline Female 70's (n=37) & 14 & 21 & 2 \\
\hline Female 80's $(n=3)$ & 2 & 1 & $\mathbf{0}$ \\
\hline Female total $(n=169)$ & 78 & 81 & 10 \\
\hline
\end{tabular}

\section{c) Statistical processing results}

The sour test result was statistically processed. Table 5 and Table 6 show the results of the comparison of the Sourness test results using TASTDISC with the tolerance range (in this study, it called the normal range) systolic and diastolic blood pressure values and others. The results did not show a statistically significant difference in either case.

Table 5: Results of statistical comparison of Sourness test results between fasting systolic blood pressure level less than 120 (Normal value) and 120 or more

\begin{tabular}{|c|c|c|c|c|}
\hline & \multicolumn{2}{|c|}{ Systolic biood pressure (mmHg) } & \multicolumn{2}{|c|}{$\begin{array}{l}\text { Tastedisc test result (Normal=1, Ovservation }=2 \text {, } \\
\text { Consultation }=3 \text { ) }\end{array}$} \\
\hline & Less than 120 & 120 or more & $\begin{array}{c}\text { Systolic blood pressure e } \\
\text { Less than } 120\end{array}$ & $\begin{array}{l}\text { Systolic blood pressure } \\
120 \text { or more } \\
\end{array}$ \\
\hline Average \pm Standard deviaton & $108.934 \pm 19.003$ & $144.616 \pm 16.889$ & $1.622 \pm 0.542$ & $1.637 \pm 0.670$ \\
\hline F test & \multicolumn{2}{|c|}{$\mathrm{P}=0.0001^{* *}$} & \multicolumn{2}{|c|}{$\mathrm{P}=\mathbf{0 . 0 1 0}^{*}$} \\
\hline \multicolumn{5}{|l|}{ Unpaired student $-t$ test } \\
\hline Mann-Whaitny test & \multicolumn{2}{|c|}{$\mathrm{P}=0.0001 * *$} & \multicolumn{2}{|c|}{$\mathrm{P}=0.821$} \\
\hline
\end{tabular}

* $\mathbf{P}<0.05, * * \mathbf{P}<0.01$ 
Table 6: Results of statistical comparison of S0urlness test results between fasting diastlic blood pressure level less than 90 (Normal value) and 90 or more

\begin{tabular}{|c|c|c|c|c|}
\hline & \multicolumn{2}{|c|}{ Diastolic blood pressure (mmHg) } & \multicolumn{2}{|c|}{$\begin{array}{l}\text { Tastedisc test result }(\text { Normal }=1, \text { Ovservation }=2 \text {, } \\
\qquad \text { Consultation }=3 \text { ) }\end{array}$} \\
\hline & Less than 90 & 90 or more & $\begin{array}{l}\text { Diastolic blood pressure } \\
\text { Less than } 90\end{array}$ & $\begin{array}{l}\text { Diastolic blood pressure } \\
90 \text { or more }\end{array}$ \\
\hline Average \pm Standard deviaton & $73.984 \pm 8.903$ & $97.180 \pm 8.329$ & $1.640 \pm 0.628$ & $1.646 \pm 0.668$ \\
\hline$F$ test & \multicolumn{2}{|c|}{$P=0.291$} & \multicolumn{2}{|c|}{$\mathrm{P}=\mathbf{0 . 1 7 3}$} \\
\hline $\begin{array}{l}\text { Unpaired student }-t \text { test } \\
\text { Mann-Whaitny test }\end{array}$ & \multicolumn{2}{|c|}{$\mathrm{P}=0.0001 * *$} & \multicolumn{2}{|c|}{$\mathrm{P}=0.919$} \\
\hline
\end{tabular}

Table 7 show the results of comparison of the bitterness test results using TASTDISC with the tolerance range (in this study, it called the normal range)

BMI and others. The results did not show a statistically significant difference in either case.

Table 7: Results of statistical comparison of Sourness test results between fasting BMI level less than 25.0 (Normal value) and 25.0 or more

\begin{tabular}{|c|c|c|c|c|}
\hline & \multicolumn{2}{|c|}{$\operatorname{BMI}(\mathbf{k g} / \mathbf{m} / \mathbf{m} /)$} & \multicolumn{2}{|c|}{$\begin{array}{l}\text { Saltness test result (Normal }=1 \text {, Ovservation }=2 \text {, } \\
\text { Consultation }=3 \text { ) }\end{array}$} \\
\hline & Less than 25.0 & 2.50 or more & BMI Less than 25.0 & BMI 2.50 or more \\
\hline Average \pm Standard deviaton & $27.548 \pm 2.143$ & $32.993 \pm 2.439$ & $1.681 \pm 0.637$ & $1.557 \pm 0.638$ \\
\hline$F$ test & \multicolumn{2}{|c|}{$\mathbf{P}=0.0001 * *$} & \multicolumn{2}{|c|}{$P=0.501$} \\
\hline \multicolumn{5}{|l|}{ Unpaired student $-t$ test } \\
\hline Mann-Whaitny test & \multicolumn{2}{|c|}{$\mathbf{P}=0.0001 * *$} & \multicolumn{2}{|c|}{$P=0.101$} \\
\hline
\end{tabular}

${ }^{*} \mathbf{P}<0.05,{ }^{* *} \mathbf{P}<0.01$

Table 8 shows the results of the comparison of the sourness test results using TASTDISC with the tolerance range (in this study, it called the normal range) Body fat and other. The results showed that there was a statistically significant difference between the normal

Body fat range and the other. Participants with a high body fat percentage were able to feel sourness at lower concentrations than those with right body fat percentage.

Table 8: Results of statistical comparison of Sourness test results between fasting Body fat level less than 25.0 (Normal value) and 25.0 or more

\begin{tabular}{|c|c|c|c|c|}
\hline & \multicolumn{2}{|c|}{ Body fat (\%) } & \multicolumn{2}{|c|}{$\begin{array}{l}\text { Saltness test result }(\text { Normal }=1, \text { Ovservation }=2, \\
\qquad \text { Consultation }=3)\end{array}$} \\
\hline & Less than 25.0 & 25.0 or more & $\begin{array}{l}\text { Body fat \% } \\
\text { Less than } 25.0\end{array}$ & $\begin{array}{l}\text { Body fatt } \% \\
25.0 \text { or more }\end{array}$ \\
\hline Average \pm Standard deviaton & $27.548 \pm 2.143$ & $32.993 \pm 2.439$ & $1.771 \pm 0.669$ & $1.579 \pm 0.621$ \\
\hline$F$ test & \multicolumn{2}{|c|}{$\mathrm{P}=0.0001 * *$} & \multicolumn{2}{|c|}{$P=0.200$} \\
\hline \multicolumn{5}{|l|}{ Unpaired student $-t$ test } \\
\hline Mann-Whaitny test & \multicolumn{2}{|c|}{$\mathrm{P}=0.0001 * *$} & \multicolumn{2}{|c|}{$P=0.020 *$} \\
\hline
\end{tabular}

* $\mathbf{P}<0.05, * * \mathbf{P}<0.01$

Table 9 and Table 10 shows the results of the comparison of the sourness test results using TASTDISC with normal Waist circumference range and the other. In Japan, the tolerance range (in this study, it called the normal range) waist circumference of the male is less than $85 \mathrm{~cm}$ (Table 9), and female is less than $90 \mathrm{Cm}$ (Table10). The results did not show a statistically significant difference in the male cases. But, in female cases, participants with a long waist circumference had a statistically significant lower sourness threshold than those with short waist circumference. 
Table 9: Results of statistical comparison of Sourness test results between waist level less than 85.0 (Normal value) and 85.0 or more for Male

\begin{tabular}{|c|c|c|c|c|}
\hline & \multicolumn{2}{|c|}{ Waist (cm) } & \multicolumn{2}{|c|}{$\begin{array}{l}\text { Saltness test result ( }(\text { Normal }=1, \text { Ovservation }=2, \\
\quad \text { Consultation }=3)\end{array}$} \\
\hline & Less than 85.0 & 85.0 or more & Waist Less than 85.0 & Waist 85.0 or more \\
\hline Average \pm Standard deviaton & $78.327 \pm 4.478$ & $91.603 \pm 4.721$ & $1.661 \pm 0.668$ & $1.712 \pm 0.716$ \\
\hline F test & \multicolumn{2}{|c|}{$P=0.334$} & \multicolumn{2}{|c|}{$P=0.286$} \\
\hline Unpaired student $-t$ test & \multirow{2}{*}{\multicolumn{2}{|c|}{$\mathrm{P}=0.0001 * *$}} & \multicolumn{2}{|c|}{$P=0.677$} \\
\hline Mann-Whaitny test & & & & \\
\hline
\end{tabular}

Table 10: Results of statistical comparison of Sourness test results between waist level less than 90.0 (Normal value) and 85.0 or more for Female

\begin{tabular}{|c|c|c|c|c|}
\hline & \multicolumn{2}{|c|}{ Waist (cm) } & \multicolumn{2}{|c|}{$\begin{array}{l}\text { Salttness test result }(\text { Normal }=1, \text { Ovservation }=2 \text {, } \\
\qquad \text { Consultation }=3)\end{array}$} \\
\hline & Less than 90.0 & 90.0 or more & Waist Less than 90.0 & Waist 90.0 or more \\
\hline Average \pm Standard deviaton & $75.729 \pm 7.477$ & $93.733 \pm 4.338$ & $1.165 \pm 0.595$ & $1.250 \pm 0.452$ \\
\hline F test & \multicolumn{2}{|c|}{$\mathrm{P}=0.0019^{* *}$} & \multicolumn{2}{|c|}{$P=0.142$} \\
\hline Unpaired student $-t$ test & & & \multicolumn{2}{|c|}{$\mathrm{P}=0.039 *$} \\
\hline Mann-Whaitny test & \multicolumn{2}{|c|}{$\mathbf{P}=0.0001 * *$} & & \\
\hline
\end{tabular}

${ }^{*} \mathbf{P}<0.05,{ }^{* *} \mathbf{P}<0.01$

\section{Discussion}

There are many reports in the past that the taste deteriorates with increasing age1). Also, the perceived concentration of taste changes with temperature 2,3$)$. In this research, we focused on sourness, but there are five basic tastes (sweet, salty, sour, bitter, and umami) 4, 5, $6)$. Also, there are various teste inspection methods7). But this time, we used TASTDISC to get a taste of sourness. The cognitive threshold of sourness examined for 298 participants (129 males and 169 females) in Yakumo-town, Hokkaido, Japan, where population migration is low. As a result, 17 males out of 129male participants (13.2\%) and ten females of 169 female participants $(5.9 \%)$ had abnormal values in sour taste test (Tastedisc) results. The tolerance range (in this study, it called the normal range) of sourness, blood pressure (systole, diastole), and body composition (BMI, body fat percentage, abdominal circumference) compared with other values. As a result, there was no statistically significant difference in the sourness threshold between the normal range of blood pressure, $\mathrm{BMI}$, and others. However, there was a statistically significant difference in the one of sourness between the normal range of body fat percentage and the other one. And also, in female cases, participants with a long waist circumference had a statistically significant lower sourness threshold than those with short waist circumference. Sourness thresholds were righter in participants with high body fat than in participants with low body fat. Our past sweet taste data show that participants with heavy body fat have high sweetness perception thersholds8). The sweetness data was statistically significantly different from the sourness data this time. Although the result was similar, in our past cognitive threshold of salty taste, there was no statistically significant item in the contents examined for sourness this time9). In the future, we would like to inspect the bitterness and umami. And, we would like to understand the actual taste sensation of the elderly by clarifying the differences between the five taste tests and blood pressure, body composition, and eating habits. We would like to obtain underlying data for preparing a diet suitable for the elderly to prevent malnutrition by grasping the taste of the elderly.

\section{Conclusions}

We obtained sour test results, TASTDISC, at the time of health check-up in Yakumo Town, Hokkaido, where population migration is low. From the database, 298 participants (169 females and 129 males) were selected form data in August 2019. The sourness test performed using the sourness test paper with liquid TASTEDISC (Sanwa Chemical Laboratory Co., Ltd) which include five different densities of Tartaric acid on a liquid with test paper namely:, 1(0.02\%), 2(0.2\%), $3(2.0 \%), 4(4.0 \%), 5(8.0 \%)$. As a result, 17 males out of 129 male participants (13.2\%) and ten females of 169 female participants $(5.9 \%)$ had abnormal values in sour taste test (Tastedisc) results. The tolerance range (in this study, it called the normal range) of sourness, blood pressure (systole, diastole), and body composition (BMI, body fat percentage, abdominal circumference) compared with other values. As a result, there was no statistically significant difference in the sourness 
threshold between the normal range of blood pressure, $\mathrm{BMI}$, and others. However, there was a statistically significant difference in the one of sourness between the normal range of body fat percentage and the other range. And also, in female cases, participants with a thick waist circumference had a statistically significant lower sourness threshold than those with a short waist circumference. Sourness thresholds were lower in participants with high body fat than in participants with low body fat. It is necessary to increase the number of participants and analyze the one in the future.

\section{ACKNOWLEDGEMENTS}

This study was supported by the research aid of Choju-iryo-kenkyu-kaihatsuhi 30-14 and the Japanese Society of Taste Technology, 2019.

\section{References Références Referencias}

1. Giuseppe Sergi, Giulia Bano, Simona Pizzato, Micola Veronese, Enzo Manzato. Taste Loss in the Elderly: Possible Implications ofr Dietary Habits. (2017) Clit Rev Food Sci Nutr 57(17): 3684-3689.

2. Barry G Green, Cynthia Alvarado, Kendra Andrew, Danielle Nachtigal. The Effect of Temperture on Umami Taste. (2016) Chem Sense 41(6):537-545.

3. Barry G Green, Kendra Andrew. StimulusDependent Effects of Temperature on Bitter Taste In Humans.(2017) Chem Sense 42(2):153-160

4. Shusuke Iwata, Ryusuke Yoshida, Yuzo Ninomiya. Taste Transductions in Taste Receptor Cells: Basic Tastes and Moreover. (2014) Curr Pharm Des. 20(16)2684-2692.

5. Isabella E Hartley, Djin Gie Liem, Russell Keast. Umami as an Alimentary Taste. A New Perspective on Taste Classification. (2019) Nutrients. 11(1): 182.

6. Ken Iwatsuki, Chiemi Nakajima. Taste Receptors in Multiple Organs. (2018) Clin Calcium 28(7): 992-997

7. Ewa Klimacka-Nawrot, Wanda Suchecka. Methods of Taste Sensitivity Examination. (2008) Wiad Lek 61(7-9):207-210.

8. Naomi Katayama, Mayumi Hirabayashi, Akemi Ito2,Shoko Kondo, Yui Nakayama, Takafumi Nakada, Seiya Goto, Satofumi Sugimoto, Tadao Yoshida3 Masaaki Teranisi, Michihiko Sone, Yasushi Fujimoto,Hironao Otake, Hirokazu Suzuki, Seiichi Nakata, Tsutomu Nakashima, Kenji Kondo, Takaki Miwa. Comparison between threshold of sweetness perception and blood pressure for resident health examination in Yakumo Town (2020) Adv. Nutr Food Sci 182(03): 1-8

9. Naomi Katayama, Akemi Ito, Mayumi Hirabayashi, Shoko Kondo, Yui Nakayama, Takafumi Nakada, Seiya Goto, Satofumi Sugimoto, Tadao Yoshida, Masaaki Teranisi, Michihiko Sone, Yasushi Fujimoto, Hironao Otake, Hirokazu Suzuki, Seiichi Nakata, Tsutomu Nakashima, Kenji Kondo, Takaki Miwa.
Comparison between threshold of saltiness perception and blood pressure for resident health examination in Yakumo Town (2020) Adv. Nutr Food Sci 181(02): 1-9 